parents who didn't take advantage of early antenatal care, but the problem is different with adults and smoking.

Dr GoDBER: The incentives will always have to be positive rather than punitive.

Mr LAING: I wonder. I agree that financial incentives are rather blunt, but what other ways can one think of to make people better citizens, which is what it amounts to?

Professor Rawlins: Is there good evidence that health education will change people's established ways of life ?

Dr Rosenthal: It depends what you call health education. The bikini and blue jeans did more to reduce adolescent obesity than any prohibition against bad nutrition.

Dr WILL: Fashion has been very much neglected, hasn't it, though it is very difficult to influence? The problem about selling a good message is that it is somehow very self-conscious in a way that immediately switches people off.

\section{Putting up the price}

Dr SMITH: This is exactly the reason why we want to get away from anxiety-provoking health education. The way to reduce the amount that people drink is by doubling the price of whisky.

Professor KLEIN: Studies do seem to suggest that there is a

\section{Working papers}

\section{Home or hospital?}

\section{SIMON BARLEY}

Often there is no choice between home and hospital: a 90-yearold with a pathological fracture of the femur must go to hospital. But there are a dozen ways to try to help the same 90 -year-old if she is demented and has a breast cancer which is fungating but localised and not metastatic to the femur. She could stay at home with help from neighbours, relations, volunteers, social workers, health visitors, and doctors, or she could go into hospital. Which hospital: the cancer ward, the geriatric ward, the psychiatric ward, the surgical ward, or the psychogeriatric ward? Or might it be something between-a social care home, a terminal care home, a private nursing home, or a sheltered flat?

The choices are not limited to the elderly. A child with acute appendicitis must go to hospital, but should he come home again the next day or stay for a week ? The middle-aged man in severe shock from a coronary goes to hospital without argument, but the choice is wider if his attack is a simple uncomplicated one and he has a wife prepared to nurse him at home. In midwifery the arguments are even fiercer. Midwifery has much about it that is simple. All the patients (at least before the birth occurs) are of one sex. The outcome is never delayed longer than nine months. The results are comparatively easy to measure. We ought therefore to have begun our research and to have decided on what grounds we can recommend home or hospital delivery. Yet there has never been a prospective trial of the results of home versus hospital confinement. I suspect that the very lack of such a trial in midwifery and the arguments which still surround the trial of home versus hospital care for uncomplicated myocardial infarction mean that medicine is listening to culture, with its resistance to fast change, and ignoring science. Before we can make firm pronouncements on the merits of home and hospital care we need much more information about the factors that influence outcome-in the patient, in the illness, in the system of medical care, and in society. The combination of these factors is not immutable, and it is in the changing balance that we must seek fresh solutions. The major change that definite relationship between price and consumption. If people want to improve their standards of living in terms of cars or whatever in a society with very slow economic growth they may have to give up other things.

Dr Rosenthal: But there is a problem. If you look at the States, blacks, who as a class are less affluent than whites, disproportionately consume more of the expensive alcohol. That is the result of marketing; it doesn't have anything to do with price elasticity.

Professor KLEIN: I always feel worried when people talk of social engineering. I don't think we know how to do it.

Dr Gray: But we do do it. The Government is engaged in social engineering at the moment by not putting up the price of alcohol and by taxing high tar cigarettes.

Dr BARLEY: Making seat belt wearing compulsory would be a very simple form of social engineering; we know that it would save a lot of lives, yet we don't do it. Why is it so unpopular?

Dr Rosenthal: States in America are repealing mandatory helmet laws as a step for individual freedom: If you want to scramble your own brains, why should anyone else care? And the answer is: because then we are going to have to take care of you.

Dr SMITH: Yes, in simple terms either we have social engineering or we may have to abandon any hope of providing comprehensive health care.

medicine must make is to stop concentrating on science alone and begin to listen more to the voice of society-our patients.

Sheffield

SIMON BARLEY, MB, MRCGP, general practitioner

\title{
COLIN GODBER
}

A major challenge to our health service over the next 30 years will be the further shift towards the care of chronic illness and disability that will be generated by the dramatic increases in the proportion of the very elderly. Our response to this will depend on the continuing consolidation of primary care, the search for alternative options in community care, and a more selective and efficient use of our costly hospital and specialist services. The range of work carried out by the primary care team will need to extend, with the other professions accepting (and being given) greater responsibility within their fields of expertise. With nurses taking on more screening and surveillance, the social worker should be tackling emotional and social problems that have responded so poorly and at such cost to the FP 10 .

As the "general physician" of the future the GP will need a different service from the specialist, more community based and with more opportunity for advice and discussion. Conversely the GP should play more part in the care of his patients in hospital.

We need also to look more closely at the arguments for a much more flexible use of domiciliary nursing to provide for intensive short-term care as an alternative to, or shortener of, hospital stay. Better selection between home, community hospital, and general hospital care in acute illness may well reduce bed occupancy, though admission rates are bound to continue to rise. In general psychiatry and mental handicap we have seen that hospital bed use can be greatly reduced if specialised day care, sheltered employment, and hostels can be developed. We 
have also seen that a unilateral hospital policy of "community care" can produce great hardship if these other options are not available.

The biggest challenge to our services in the future, however, will be the chronic illnesses of advanced age. With major preventive advances unlikely our response will have to be through better co-ordination of services on a district level. In the community we will look to the primary care team for careful surveillance of those at risk, particularly families who are looking after the disabled elderly; support for neighbourhood voluntary schemes; and the provision of a range of domiciliary and daycare services. The major priority in capital development will be sheltered housing, which with enhanced staffing may take over much of the role of our present residential homes. They in turn are likely to specialise in the care of the very frail, integrating much more closely with the long-stay provision of the hospitals.
The aim of operating such a spectrum of care will be to minimise the overloading of those at its less intensive end, particularly the caring family. This will mean a high priority for short-term rescue in the form of extra home nursing or brief residential or hospital care. Thus to maintain the disabled elderly in the community we will need, paradoxically, a high rate of short-term hospitalisation. This will need far better coordination of the housing, health, and social services than exists at the moment. And given the necessary investment to allow them to underpin the acute (as well as chronic) hospital provision for the frail elderly, specialists in the medicine and psychiatry of old age could provide the vital hub for this integration.

Southampton

COLIN GODBER, BM, MRCPSYCH, consultant psychogeriatrician

\section{Discussion}

Dr BARLEY: Patterns of use of home and hospital are going to have to change, and the major factor promoting this change is the demographic changes. Is there anything we can do to engineer the change in an orderly fashion? There are several ideas that will enable us to use our resources, particularly in the community, in a better way-for example, the hospital at home, which the French have used extensively in cities. With a more flexible bridge between hospital and home care you can get patients from one to the other much more easily, which should speed their recovery a great deal.

There will also be pressures on hospitals to use their resources more economically - for example, to operate day surgery, five day wards, and pre-anaesthetic assessment.

Dr GodBer: That takes a lot of co-ordination. Similarly, this is a major reason for concentrating on specialties like psychogeriatrics and geriatrics, because perhaps a third of our time is going to be spent on administration and liaison to keep the service going. And other hospital specialists are going to have to concentrate much more on their own technical fields, and perhaps get more use out of their services during the 24 hours -perhaps EMI scanners can be used for 24 hours instead of just eight. They've got to concentrate on economy and the need for short stays.

Dr BARLEY: The difficulty about an anaesthetist coming to anaesthetise a patient assessed by me is that it would take a long time before he'd accept my assessment rather than his own or that of his surgeon colleague's houseman.

Dr WILL: One of the elements of good medical care is that the people practising translate information about the patient into their own framework of reference. This is why information from the GP is repeated, because it is transmuted culturally into hospital terms.

Professor DudLey: There are certain areas of data that I don't think we'd have any trouble transmuting into our experience. If I get to know from the GP that the patient is hypertensive or has respiratory disease then I can organise his care as an inpatient quite easily. But I rarely get told. That's different from telling me there is something wrong with the patient.

Dr GoDBer: Would it not be more logical if the GP, knowing the patient needed a hernia repair, discussed the problem with the chest physician before he even presented him for surgery, found out what needed sorting out, and then told the surgeon and anaesthetist. Unless we start running our services on the basis that the GPs orchestrate them then I don't think we are going to get the balance between primary and secondary care right.

Dr GRAY: We've been talking about the hospital as if its role was to do with medical treatment and operations. But much of the work of hospitals is just as nursing homes-postoperatively and in admitting people to relieve the family. We should make more use of old people's homes, which are de facto nursing homes. If they were properly staffed and equipped then $25-30^{\circ}{ }^{\circ}$ of the beds could be short stay.

Professor KLEIN : One of the problems of home versus hospital is the implications of still more participation in the labour force by women, which makes the care of people in the community much more difficult. Aren't we half way through a social revolution externalising the unpaid work that used to be done in the home and turning it into a personal social service ?

My bet is that (given continuing high unemployment) there will be pressure for the public sector to take on more labour, particularly at the low paid end, where it doesn't make much difference whether people are on the dole or not. There will be a fair amount of semi-skilled labour about, able to give some support, but in the paid sector rather than in the family.

Dr GoDBER: I don't see the less skilled pairs of hands being deployed in the hospital so much as to bolster up the community nursing and hospital at home type of service.

Dr BARLEY: But are we going to see the logical corollary of this, which is closure of some of our hospital beds? Some geriatric beds in general hospitals could close, provided the resources used to run the beds were put into the community.

Dr SMITH: If you close those beds from their current use and begin to use the capital facilities-the operating theatres and investigatory departments-round the clock then you are going to need many more beds to provide for patients using the 24 hour service. This would mean totally closing some hospitals, because there's no point in increasing the work load of every pathology laboratory by working it 24 hours a day. We want to reduce the number of laboratories and increase the output of the remaining ones to compensate.

Professor DUDLEY: In terms of industrial relations and community feeling, I don't think it's a practical proposition to close hospital beds.

Dr GODBER: I don't think there'll be a need to close beds. In most places there are too few geriatric beds. What is important is that we invest in the future for extra care of the elderly. We should put resources into community services and use existing hospital facilities and residential care to offer a more responsive service to back that up.

\section{Sharing medical responsibility}

Dr GoRdON MACPHERSON (13): Is it a practical possibility for the therapeutic services to come out into the community?

Professor Rawlins: Yes, but I think the problem with home and hospital (rather than home or hospital) is the sharing of 
responsibilities. It's not traditional medical practice in Britain to share medical responsibility and it would require a considerable change in attitude and a lot of trust.

Professor KLEIN: Is it professionally unimaginable that there should be a protocol to be followed before a GP sends someone to a consultant?

Professor DudLey: I can give a good example of this in relation to our interaction with a pathology laboratory. We agreed exactly what we wanted to know about every patient with carcinoma of the breast. Now that system is established there's no problem.

Dr GoDBER: Over the next 30 years we hope that some of the best things that are happening now in terms of interactions will generalise themselves in the Health Service.

Professor DUDLEY: The great difference between here and America is that here there are no financial incentives.

Dr BARLEY: I think there are professional incentives and that these are more desirable than financial ones. There are incentives for GPs in vocational training. Trainees see what good general practice can be, but put them in their definitive practice and they may not have a ghost of a chance of applying this because they will be the junior partner in a hierarchy. If GPs could go into their first practice as independent practitioners then they would have enormous flexibility to innovate.

\section{Innovation and flexibility}

Professor KLEIN: We are talking about innovation that actually involves changing the character of organisations-changing the way that teams work and that relationships work-orchestrating more. And this is very difficult. Are we training medical students to ensure that they'll be able to adapt and cope with change and be flexible?

Professor DudLey: There is very little attempt to train students in the art of handling uncertainty.

Dr KRAFFT: Presumably the opportunities for women are going to be important if they are going to represent half of all medical students.

Professor KLEIN: This might have much larger implications.
If you create enough flexibility for women to pursue their careers then it might be possible to create more flexibility within the profession generally. If you are interested in innovation and flexibility one way of getting it is by actually moving people around.

Dr WILL: One's very attracted by this idea of mobility. It would be interesting to see whether administration would be more effective if administrators spent fairly long periods working at the sharp end. You have to weigh the dislocation of doing that in established structures against the novelty and energy that it releases to improve things afterwards. People tend to look at fixed solutions as if there were some kind of institutional arrangement which would be perfect in some sort of sense. Instead, I hope people remain highly pragmatic and feel their way towards solutions, remaining aware that solutions are not eternal but merely suit the period.

\section{Appointments of speakers}

(1) Dr Tony Smith, MA, BM, deputy editor, BMF.

(2) Dr Colin Godber, BM, MRCPSYCH, consultant psychogeriatrician.

(3) Dr Jennifer Longworth Krafft, $\mathrm{MB}$, BS, registrar in morbid anatomy.

(4) Professor Hugh Dudley, CHM, FRCS, professor of surgery.

(5) Mr W Laing, BSC ECON, economist.

(6) Professor Rudolf Klein, MA, professor of social policy.

(7) Dr Gerald Rosenthal, director, National Centre for Health Services Research, Washington, USA.

(8) Dr J A Muir Gray, MB, DPH, registrar in community medicine.

(9) Professor Michael Rawlins, MD, FRCP, professor of clinical pharmacology.

(10) Dr E J Will, BM, MRCP, honorary senior registrar.

(11) Dr Simon Barley, MB, MRCGP, general practitioner.

(12) Dr Stephen Lock, MA, FRCP, editor, BMF.

(13) Dr Gordon Macpherson, MB, BS, deputy editor, $B M \mathcal{H}$.

\section{MATERIA NON MEDICA}

\section{Rural culture}

Suffolk is dismissed as being flat and uninteresting by the uninitiated - "furruners" we call them. It certainly has nothing to compare with Scafell or Snowdon, but you cannot see the lighthouse at Southwold from Bury St Edmunds: two points chosen with real ale drinkers in mind. In fact, it is probably better to be at Southwold with your pint and look the opposite way, if you must. You can, however, see Blythburgh church, "the cathedral of the marshes," for some miles around and even better when it is illuminated at dusk, standing majestically amongst the mudflats and reeds. It is a popular sight at this time of the year as people wend their way from all over England to North-east Suffolk for the pleasures of the Aldeburgh Festival. Aldeburgh was until the last war better known for being an ancient fishing town mostly consumed by the sea, such are the scouring qualities of the North Sea tides around these parts. The Victorians considered it a fine watering place and have left their mark with their somewhat bizarre buildings. Now it is known throughout the world as the home of Benjamin Britten and the music festival he founded.

The main programme has moved out to Snape, a small village blessed with a noble maltings now converted to a concert hall with superb acoustics and adjacent training and residential accommodation. Animal foodstuffs still fill part of the mill complex and occasionally a sailing barge will tie up alongside the quay. The fine music within this industrial cathedral is so enhanced by the surroundings. Before one is an uninterrupted vista of waving reeds, gently lapping water and shelduck settling down to roost for the night. To the right is Hepworth's stark trio "Family of Man." The air is clean and wholesome, the memories sweet. Alas, Benjamin Britten can no longer preside. He lies in his beloved Aldeburgh: a simple headstone of slate and posies of flowers mark his final resting place. What finer monument than the Aldeburgh Festival ? - P D sIMmons (senior registrar, London).

\section{Owl diary}

Spring-Soon after moving to our present house we were woken early on a clear, bright morning by the more than usually agitated chatter of blackbirds. Thinking it must be our cats I went downstairs to investigate. Among the young green leaves of the giant beech tree outside our bedroom window sat a majestic tawny owl, staring at me unblinking from thirty feet away. As I watched he took off and flew sedately across the garden in spite of the blackbirds' mobbing to settle in a large oak. I closed my eyes and opened them again. No, I wasn't seeing double. There were now two owls perched close together on the same branch.

Summer-In the evening dusk there came an excited cry from the bottom of the garden. When we arrived we found not two but three owls, one of which appeared larger than the others because its fur was fluffed out like a woollen ball. Its clumsy movements and plaintiff cries confirmed its immaturity, but by the autumn we could no longer distinguish parents from young, and soon there were only two again.

Winter-As the leaves fell we saw them less often but heard their hooting at night. The discovery of food pellets under the yew in the middle of the garden suddenly made it all clear. We had been singled out because this was the only patch of evergreen among the winter skeletons. I spoke to a colleague who knew the house about the pleasure we got from the owls. "Their hooting nearly drove us mad when we lived there as students 25 years ago" he said. How long do owls live, I wondered. Could these be the same ones?-ALEX PATON (physician, Birmingham). 